\title{
Ser professora: Representações e identidades no contexto da cultura visual
}

\section{Resumo}

A temática desta reflexão trata da desconstrução de um padrão que normatiza o ser professor universitário a partir de artefatos da cultura visual de uma instituição de ensino superior. Para tanto, foram utilizadas como fonte de dados entrevistas realizadas com professores/as colaboradores/as, recém ingressantes, na Universidade Federal de Goiás UFG, entre os/as quais a pesquisadora se inclui tanto como respondente, quanto como recém ingressante na mesma instituição. Para todos/as foi perguntado "Você se considera educador/a?"; como segunda fonte, foi analisado o Jornal UFG, na sua comemorativa $50^{a}$ edição, buscando a partir das fotografias dos/as seus/suas professores/as, como a instituição constrói as representações deles/as. Como resultados, serão apresentadas as análises dialogadas com referenciais bibliográficos objetivando compreender como algumas representações sociais do que é ser professor universitário interferem na prática docente da pesquisadora.

Palavras-chave: Cultura Visual; Representação social; Ser professora universitária

\begin{abstract}
The theme of this reflection is the deconstruction of a pattern that regulates the professor be artifacts from the visual culture of an institution of higher education. So, were used as a data source interviews with teachers the newly entering as employees at the Federal University of Goiás - UFG, which I include myself both as researcher and as respondent, and as new entrant in the same institution. For all I was asked "Do you consider yourself an educator?"; as a second source, we analyzed the Journal UFG in its commemorative 50th edition, searching from the photographs of his teachers, as the institution constructs representations of them. As a result, the analyzes will be presented dialogued with bibliographical references aiming to understand how some representations of what being a university professor teaching practice interfere with the researcher.
\end{abstract}

Keywords: Visual Culture, Social representation; Being a university professor

\section{Primeiras palavras}

Ser professora nunca foi para mim uma tarefa fácil. Quando iniciei minha trajetória docente, numa instituição de ensino superior, senti a responsabilidade de tão jovem estar a explicar sobre conteúdos a grupos, em muitos casos, mais velhos do que eu. Fui criticada por alguém próximo a mim, que certa vez me disse: "você devia ter começado no ensino médio ou fundamental". Com o passar dos anos, notei que não se tratava do grau no qual eu me propunha trabalhar, mas de uma determinada representação que construí sobre o que é ser uma professora universitária. Descobri em seguida que não construí esta representação sozinha, ela é fruto sim de uma série de 
práticas docentes que vi os meus professores realizarem ao longo da minha jornada estudantil, mas é também e, sobretudo, resultado de certo padrão normativo disseminado socialmente sobre o que é ser professor universitário. Este padrão, que argumento aqui ser uma construção cultural, tem, portanto, seu viés político impregnado.

Ao ministrar aulas em faculdades privadas, não se tem muitos privilégios num campo de ensino específico, tornando-se um feirante de saberes. É difícil promover aprofundamentos neste contexto. Aliado a isso, a imagem de que uma professora, aquela domina conteúdos diversos e é quase uma enciclopédia ambulante, pesou sobre meus por tempos a ponto de quase abandonar a profissão por não lidar bem com saber tanto sobre disciplinas tão diversas, a cada semestre. Hoje, de volta ao ambiente acadêmico, em uma universidade pública, disposta a viver o ensinar com mais leveza, reinvento-me como professora cotidianamente. Neste processo de reinventar-me noto que é preciso cautela, pois como disse acima, a representação de professora universitária não é apenas minha, mas, sobretudo, social.

Como optei com trazer a educação da cultura visual para meu contexto de sala de aula, ao trabalhar com audiovisual e teorias da imagem, lido constantemente com a desconstrução do simbólico, incluindo-me nela. Mas aqui não tratarei propriamente sobre como faço isso com meus/minhas alunos/as. Antes me interessa nesta reflexão investigar a partir de leituras e revisão bibliográfica em diálogo com um documento institucional, o Jornal UFG - Publicação da Assessoria de Comunicação da Universidade Federal de Goiás - UFG, enfocando no modo como este constrói visualmente a representação de seus professores. Acrescido a estas duas fontes, insere-se uma terceira, as auto-atribuições que um grupo de professores recém-chegados na referida instituição, entre os quais me incluo, que durante uma entrevista, constroem sobre seu próprio ser professor/a.

Para esta reflexão, interessa-me por em perspectiva as representações visuais que o Jornal UFG, 50ª edição, março 2012, constroem sobre ser professor, para esta e nesta instituição. O referido volume encontra-se disponível no sítio da Assessoria de Comunicação da Universidade Federal de Goiás ${ }^{1}$. No mês de junho, deste mesmo ano, durante uma entrevista realizada com sete professores recém-chegados - todos com no máximo três anos de ingresso - nesta instituição de ensino, escolhidos aleatoriamente e vinculados a cursos distintos, aos quais perguntei, e também respondi, "Você se considera educador/a?". A partir de uma análise comparativa das respostas, pretendo compreender sobre o significado dessas auto-atribuições.

Interpreto as fotografias da $50^{a}$ edição do Jornal UFG a partir de uma adaptação 1 Trata-se de um Jornal que comemora a 50a edição e pode ser visto e lido na íntegra em
$<$ http://www.ufg.br/uploads/files/Jornal UFG 50.pdf $>$. 
da estratégia pedagógica cunhada por Mitchell (2003), de Showing Seeing. Utilizada no contexto de aulas na graduação, o teórico da Cultura Visual compreende-a como um processo performático em que os estudantes se apresentam aos demais como um etnógrafo que é reportado a uma sociedade que concebe a Cultura Visual e volta a sua, que não a concebe. Obviamente trata-se de um exercício de imaginação, no qual este suposto etnógrafo tem que apresentar aos conterrâneos explicações sobre os artefatos visuais que conheceu, considerando que eles não possuem qualquer familiaridade com "noções tanto como cor, linha, contato visual, cosméticos, roupas, expressões faciais, espelhos, lentes, ou voyeurismo, quanto como fotografia, pintura, escultura ou qualquer outra mídia visual" e neste exercício a "cultura visual é então feita para parecer estranha, exótica, necessitando de explicação" (Idem, p. 176, tradução livre). O esforço exigido pelo Showing Seeing, portanto, consiste em explicar significados contidos tanto nos artefatos visuais, quanto na relação que a sociedade visitada pelo suposto etnógrafo estabelece com eles. Assim, o objetivo é exigir do etnógrafo performático um esforço em compreender para explicar o artefato visual para além dele mesmo, ou seja, considerar também os significados estabelecidos pela sua inserção no contexto de relações culturais.

Para estas análises, portanto, pretendo imaginar-me neste esforço etnográfico para pensar o ser Professor/a, na perspectiva do artefato Jornal da UFG, bem como das auto-atribuições de professores recém-chegados à instituição. Estas duas fontes, por fim, serão mediadas por leituras e revisões bibliográficas e pelas minhas vivências no contexto da pesquisa, ao qual este texto se insere.

\section{Ser professor/a: entre identidade cultural e representações sociais}

Quando lanço a questão "Você se considera educador/a?" a um grupo de professores, no qual me incluo, obtenho como respostas,

Sujeito 1: Eu me comprometo com isso e quando eu vejo alunos que eu me propus formar exercendo seus trabalhos e me chamando de professora e dizendo "você sabe que eu fui sua aluna?", eu acho que de repente eu tenho conseguido fazer isso. Eu tive uma experiência super interessante na SBPC ${ }^{2}$, um aluno que estava no estande trabalhando me chama e fala assim "Oh professora, lembra de mim? Eu fui seu aluno". Aí, eu olhei para ele e eu me lembrei e disse "Nossa que legal, você está trabalhando aqui". Ele respondeu "Tô, eu passei no concurso do governo". E ele me disse "Professora, você sabe que a última vez que eu colei? Foi naquele dia que você não foi aplicar a prova e pediu para um professor aplicar a prova para você. Você tinha ido para um congresso e quando chegou, viu as notas altas e concluiu que a gente tinha colado. Então disse pra gente que não tinha como tirar

2 A Sociedade Brasileira para o Progresso da Ciência - SBPC - é uma entidade civil, fundada em 1948, que se autoatribui agente nos debates que determinam os rumos das políticas de Ciência e Tecnologia e da Educação no Brasil. Vide <http://www.sbpcnet.org.br/site/asbpc/mostra.php?id=473\&secao=303 > . 
as notas porque você não estava fiscalizando a prova, mas você disse a seguinte frase 'Se você cola, você nunca vai saber o quanto você vale'. E professora, aquilo entrou na minha cabeça e eu nunca mais colei". Eu acho que é isso. [...] A gente nunca tem feedback completo, mas na hora que eu ouço isso, eu acho que eu estou conseguindo porque o educador está formando seres humanos. Para mim ele não está formando profissionais, ele está formando seres humanos [...] eu aprendi com meu professor de técnicas comerciais que quando a gente para de crescer e sonhar já pode morrer $[\ldots]$

Sujeito 2: Eu tenho isso formatado claramente, fisicamente e na estrutura mental mesmo de qual é o meu projeto educacional onde eu quero pegar o aluno; de onde eu pego ele e até onde eu quero chegar e o que eu preciso atingir. Agora eu, na maioria das vezes, não estou atingindo devido a coisas que nós falamos [anteriormente]. Eu não tenho essa bondade, essa particularidade de pegar meus alunos e dizer "olha vamos ali para a tribo que vocês vão ver o social, vão ter uma aula espetacular nessa área". O máximo que eu consigo é levar para uma visita técnica, por exemplo, como numa empresa e muitas vezes ainda tem alguns problemas que quando chegamos a lá a empresa nos mostra coisas que são totalmente erradas.

Sujeito 3: Eu também tenho projeto educacional sim e ele expande a dimensão da sala de aula, embora enquanto educadora e pesquisadora eu não abro mão do laboratório bem equipado, mas sou antropóloga, trabalho com aldeamentos, trabalho com indígenas e não com tribos, mas aldeamentos. Mas eu formo pesquisadores, eu não formo índios. Eles [os pesquisadores] precisam de tecnologia avançada e eu faço questão de laboratórios na universidade. [...] Eu já tive oportunidade de dar aula fora do Brasil e foi muito interessante porque foi no México enquanto o pessoal [das políticas educacionais] aqui está olhando para os Estados Unidos muito de perto, eu sou latino americanista [...] trabalho do México para baixo [...] e eu realmente não posso deixar de reconhecer que aqui no Brasil a gente tem condições técnicas, tecnológicas e humanas melhores [...] no Chile, você ainda dá aula em cima do tablado, o professor ainda usa tablado para dar aula, a gente já conseguiu romper com isso, romper um pouquinho com o pedestal [...] agora somos professores do ensino superior e formamos pesquisadores. Assim formamos profissionais nas nossas áreas e aí eu insisto que eu preciso de laboratório, não formo índio, eu não formo negro, eu não formo mulher, eu formo pesquisadores, antropólogos, cientistas sociais que precisam de recursos altamente tecnologizados e, nesse sentido, eu me considero sim educadora porque a educação extrapola a sala de aula no sentido de que eu busco dialogar. Eu sou professora, eu sou pesquisadora, mas eu sou militante também. Eu sou ativista do movimento negro e ali no movimento negro eu consigo inaugurar um diálogo político que é cortado também por um comportamento que zela pela relação ensino e aprendizagem. Sou ativista do movimento de mulheres, então desse comportamento sou educadora, sou mãe, e tudo isso perpassa as minhas ações. [...] É, nesse sentido eu me considero uma educadora sim. Agora, que cometo um milhão e meio de falhas na execução desse projeto, cometo. Porque é tudo muito dinâmico e as relações são 
muito únicas, então eu não consigo pensar ainda fórmulas. Eu sempre cometo falhas nesse processo, sempre tem problemas. Agora eu acho que eu ganho quando eu coloco esses problemas na mesa e começo a pensar sobre eles para ver se na próxima sai um pouquinho melhor, né? Isso dá muitos problemas, tem problemas de escassez de recurso, tem problemas relacionais, tem problemas políticos, ideológicos, morais, éticos e outros e aí a gente vai tentando administrar para garantir a relação, que é uma relação favorável a esse espaço de ensino e aprendizagem.

Os trechos da entrevista, cujos entrevistados optaram por não se identificar, preferindo eles mesmos a utilização do termo "Sujeito" seguida de numeração, estão aqui dispostos na mesma sequência como ocorreram, primeiro respondeu o Sujeito 1, depois o Sujeito 2, o 3 e segue. Entre a resposta de um Sujeito e outro, outros assuntos foram discutidos, os quais não interessam a esta reflexão. Busquei, por isso, editar a partir da questão exposta acima, as respostas que a abordam. Noto na resposta do Sujeito 1, uma percepção de que educador e professor sejam, ao mesmo tempo, conceitos distintos e complementares. A utilização do termo educador na pergunta foi intencional, na medida em que o termo professor/a, no contexto da entrevista, me pareceu não comportar a perspectiva bem enfatizada pela resposta do Sujeito 1, que é a de que educador não forma apenas profissionais, forma seres humanos. Ressalto a intenção de ampliar certa compreensão muito corriqueira que considera professor como aquele que ensina e educador como aquele que se ocupa, para o exercício desta função, dos aspectos diversos da aprendizagem, de modo que a distinção entre professor e educador equivaleria a distinção de enfoques dadas aos estudos de ensino e os de aprendizagem.

Embora tivesse esta intenção, percebo, na resposta do Sujeito 3, que os termos parecem ser similares, precisando avaliar o contexto para distingui-los. A auto-atribuição é de educadora, neste caso, mas também de professora. A segunda aparece ao se vincular ao local de exercício desta função, ou seja, o ensino superior; já a primeira ao argumentar sobre um extrapolar deste local, que é para além das salas de aula. Neste depoimento, noto que ser professor é se manter dentro o local de ensino e ser educador é extrapolá-lo por agregar ao local e suas funções requisitadas, outras, como os adjetivos de pesquisador, antropólogo e cientista social, todos classificados como profissões.

Neste sentido, para o Sujeito 1 , é possível ensinar os estudantes a ter uma profissão, sem abrir mão de educá-los por meio de valores éticos, como ilustrou com o exemplo da cola e o relato de seu professor de técnicas comerciais. De certo modo, o Sujeito 1, compreende que como professor também educa. E que se identifica, por se comprometer com estas questões éticas, com estas duas funções.

Apesar de afirmar que possui um projeto educacional com clareza, com a resposta 
do Sujeito 2, posso compreender que formar seres humanos seria incompatível a tal projeto, uma vez que não se identifica com uma possível bondade de mostrar o social para os alunos, exemplificando que não é cabível levá-los a uma tribo indígena. Noto que para o Sujeito 2, educador é representado pela bondade e pela capacidade de ensiná-la na relação com um Outro, um diferente, que aqui ele exemplificou com o uso do indígena. Ou seja, o Sujeito 2 não compartilha com uma romantizada bondade vinculada por ele a representação do educador, pois tem claro como o estudante chega e como tem que sair de seu projeto educacional. Fica implícito que não se identifica com uma suposta responsabilidade ética atribuída ao educador pelo Sujeito 1, antes disso, parece compreender que seu papel é apresentar técnicas corretas de trabalho, de modo a questionar o potencial instrutivo de uma empresa que possui problemas técnicos.

Em reação a resposta anterior, o Sujeito 3, cujo cotidiano de ensino e pesquisa abrange a relação com o Outro, esse diferente, adverte quanto ao uso equivocado de tribo para designar o agrupamento deste Outro, que enfatiza "aldeamentos". Desse modo, se apresenta como educadora, e também se designa pesquisadora, latino americanista, professora, militante, ativista do movimento negro, ativista do movimento de mulheres, sobre o qual argumenta que apreende um comportamento de educadora, que vai perpassar inclusive seu ser mãe e suas atividades profissionais. Este comentário é sintomático na medida em que se construiu pela necessidade, que argumento adiante com Lap (2004), de se diferenciar do Sujeito 2, que, por sua vez quis se diferenciar da autoatribuição do Sujeito 1 ao se designar comprometido com uma formação de seres humanos. Estaríamos diante de exemplos de mito comum sobre o Outro?

Quando Lap (2004, p. 81, tradução livre) discute, a partir de uma celebrada obra literária vietnamita, o mito comum sobre o Outro, apresenta-o ressaltando a dialética de um Outro, ao mesmo tempo, igual e diferente de nós, de modo que "temos sempre necessidade de um Outro para afirmar nossa existência. É sempre o contato, a troca e o conflito que nos ajuda (e nos obriga) a nos conhecer e reconhecer os Outros". Por isso, a questão da identidade se justifica entre o eu e o Outro, seja pela afirmação, distinção ou oposição. Os interesses de Lap, poeta e ficcionista vietnamita, no referido texto giram em torno da identidade cultural das comunidades em um contexto de mundialização. Ao fazer uso do mito comum sobre o Outro como ponto de partida para refletir sobre a identidade de comunidades, o autor se apresenta para nós, ocidentais, como o Outro, o oriental.

Com Lap (2004, p. 83) é possível pensar a identidade cultural das comunidades como "uma forma de reduzir a realidade a alguns de seus aspectos", sendo significada a partir "de um único e imutável mito: o mito do Outro". Quando o autor se utiliza do mito do Outro o faz pensando na tendência que temos de dizer o que alguma comunidade é, o 
que implica em simplificações, podendo chegar a equívocos de invariabilidades. O autor exemplifica estes pontos ao nos lembrar das noções generalizadas de oriente e ocidente, as quais são impregnadas de preconceitos, imbuídas de equívocos valorativos e estanques ao longo da história.

Em primeiro lugar, o autor sugere que tais noções apresentam um oriente fundamentado em um conceito geográfico, cujas significações históricas datam de bem pouco tempo, uma vez que até o século XIX, na Europa, designava-se oriente toda a dominação do império Otomano. Outra significação de oriente, segundo o autor, foi de países cujos regimes não eram capitalistas, durante a Guerra Fria. Ainda outra, numa perspectiva cultural, define oriente como conjunto de civilizações que permanecem fiéis ao espírito tradicional, prevalecendo o irracionalismo e o interesse pelos assuntos espirituais. Na mesma perspectiva cultural, o ocidente é definido pelo racionalismo, individualismo, corrupção e materialismo.

É preciso esclarecer que o autor apresenta estas significações como concepções generalizadas, redutoras e tomadas, muitas vezes, como invariáveis na história e no território das comunidades. Por isso, argumenta que diferenciamos a identidade das comunidades segundo diversos níveis, como família, raça, nação, religião, língua do mesmo modo que construímos a divisão do mundo em designações como oriente e ocidente, norte e sul. Ou seja, estas diferenciações identitárias podem ser compreendidas como construções culturais sobre o Outro, as quais se tornam significativas a partir destes níveis com os quais o reduzimos a generalizações que, muitas vezes, se tornam invariáveis. Desse modo, quando tentamos uma significação sobre os brasileiros, por exemplo, o autor vai advertir que estamos desconsiderando diferenças incalculáveis existentes entre tal e tal brasileiro. Por isso é imprescindível que ao perceber estas significações construídas sobre o Outro, tenhamos em perspectiva a relatividade delas, uma vez que são incapazes de responder pela diversidade que as identidades culturais comportam.

Obviamente que Lap não está tratando sobre a identidade cultural de um sujeito, mas pergunto, as auto-atribuições presentes nas respostas anteriores dizem respeito apenas às identidades culturais dos indivíduos que se auto-atribuíram? Parece-me que não. A relação entre uma resposta e outra, analisada pelas reações em razão de um conceito do que é ser educador e do que é ser professor, esteve presente em toda a sequencia do trecho de depoimentos. De certo modo, poderíamos pensar, para este grupo, que a relação entre sua auto-atribuição está vinculada a certa representação cultural do que é ser educador e do que é ser professor. Neste sentido que Penna (1992), ao pensar a questão da identidade procura fazê-lo pela via da representação social. Tal via, segundo a autora, superaria versões clássicas da teoria da identidade as quais 
acabam por sugerir uma identidade social única, vinculada necessariamente a momentos históricos específicos, como a formação do Estado nacional, a construção simbólica de um povo. Assim, prefere a concepção de identidade enquanto representação simbólica ou imaginária, alertando para um problema advindo do fato de pouco problematizarmos sobre o que tais termos significam. Penna (Idem, p. 57) apresenta que

Para evitar esse problema, convém retomar rapidamente os conceitos que servem de base ao nosso tratamento das questões de identidade. Embora buscando o sujeito de age, pensa e atribui identidades, optamos por inseri-lo social e culturalmente, e portanto descartamos os referenciais da psicanálise, relativos ao inconsciente e seu funcionamento, mais adequados para o tratamento da identidade pessoal e da individualidade, que não constituem nosso objeto de estudo. Privilegiamos, portanto, as abordagens teóricas que remetem aos processos sociais, sem no entanto reduzi-los a seus aspectos materiais.

Assim, como a autora busca inserir social e culturalmente o sujeito que age, na sua investigação? E quais seriam estas abordagens teóricas que evitam reduzir os processos sociais aos seus aspectos materiais? Mas antes de buscar, no diálogo com a autora, respostas, interessa-me observar as ilustrações abaixo.

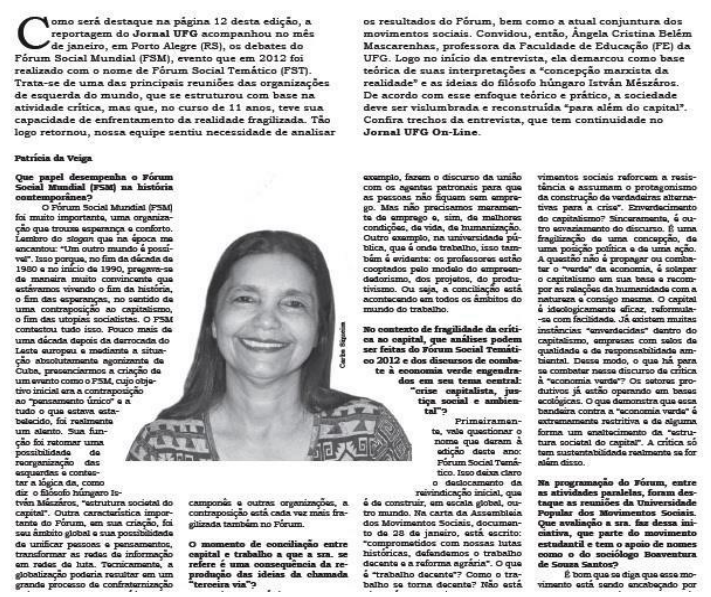

Figura 01: Recorte da Página 3, Jornal UFG

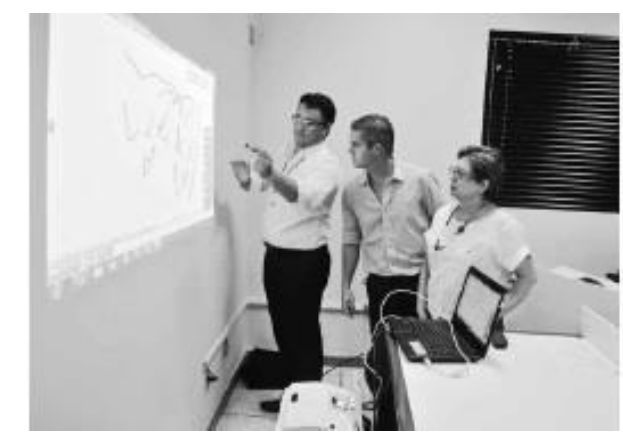

Figura 02: Recorte da página 4,

Maria, Ano VI - Número 10 - Março de 

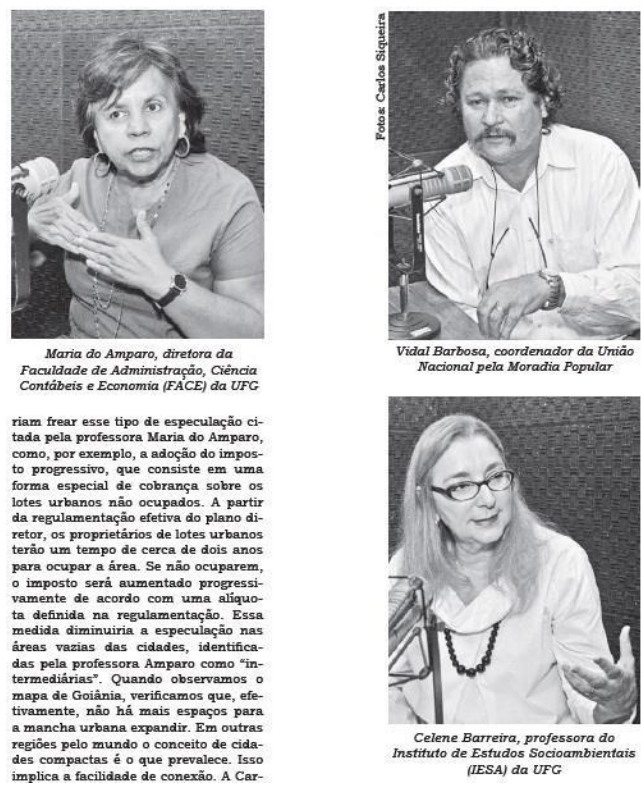

Figura 03: Recorte miolo de página dupla, páginas 5-6, Jornal UFG

As figuras acima apresentadas são um recorte do Jornal UFG, 50a edição comemorativa, tendo optado por incluir aqui momentos em que professores da instituição apareceram. Nem todas as ilustrações da edição comemorativa que continha professores estão aqui. Realizei uma edição para fins desta reflexão, uma vez que a partir da adaptação da pedagogia estratégica Showing Seeing de Mitchell (2003) a cultura visual é estranha e exótica, carecendo de ser explicada ao/a leitor/a deste texto.

O Jornal UFG é uma publicação institucional da Universidade Federal de Goiás. A edição comemorativa traz reflexões sobre o próprio jornal, ao longo dos seus seis anos de existência periódica. É impresso em suporte chamado papel jornal, com algumas páginas coloridas, reproduzindo as matizes diversas que nosso olho é capaz de observar quando vê uma paisagem natural. Tem suas páginas divididas por sessões, cujo conteúdo é apresentado em formato de textos e imagens, fotográficas ou ilustrações gráficas. Por fotografia entendo um artefato visual que se utiliza da escrita pela luz, ou seja, da sensibilização da luz em um suporte sensível a ela, de modo a reproduzir, de acordo com o recorte intencional a composição escolhida pelo fotógrafo; por ilustrações gráficas entendo os traços retos, curvos e pontilhados feitos à mão ou por intermédio de uma 
máquina denominada computador, retocada e colorida em um programa de edição de imagens vetoriais.

Nesta edição comemorativa, a capa apresenta uma montagem de diversas capas de edições anteriores em um formato circular; na página dois denominada Destaque, temos o Editorial e o Campus em Foco, com textos curtos em formato de notas informativas; a três é denominada Entrevista e traz trechos contendo perguntas e respostas à professora da UFG, Ângela Cristina Belém Mascarenhas, vide recorte em Figura 01, acima; a quatro é denominada Vida Acadêmica, que trata da temática planejamento institucional, de onde recortei a Figura 02; a cinco Odontologia; a seis e sete são o miolo ou páginas centrais do jornal, é denominada Mesa-redonda, na qual duas professoras da UFG, Maria do Amparo e Celene Barreira, e o coordenador da União Nacional pela Moradia Popular, Vidal Barbosa, debatem; a oito e nove são denominadas unicamente por Pesquisa e Patrimônio; a dez trata do Aniversário do jornal e a onze é chamada Homenagem, abordando quem participa da feitura do jornal; a doze chama-se Política; a treze, Interior; a quatorze, Em tempo; a quinze, Universidade; e a dezesseis, Fotojornalismo, que apresenta fotografias marcantes ao longo destas 50 edições do Jornal UFG.

Interessa-me voltar agora às figuras 01,02 e 03, exibidas acima, observando que todas as três trazem representações de professores da UFG. Como estas representações foram construídas? Que diálogos elas estabelecem com os outros elementos de significação em um jornal institucional, como o texto, as dimensões das imagens, os sentidos apreendidos nelas mesmas a partir de sua composição e, finalmente, as relações sociais que podem ser construídas com elas?

A figura 01 traz a fotografia de uma professora da UFG cujo conteúdo do texto é construído em formato de entrevista. Nesta, a palavra-chave é conciliação, o que a fotografia representa bem na composição harmônica de um sorriso doce nos lábios da professora, na sua expressão facial leve e também na arejada diagramação dentro do texto, de modo que o texto e a imagem não apresentam ruídos que promoveriam incômodos ao olharmos para a página como um todo. Em termos de dimensão, a fotografia está equilibrada, em local centro-esquerdo-superior da página. $O$ fato de ter sido recortada, ou seja, o plano de fundo da imagem ter sido retirado dela, possibilita a compreensão de que a professora estaria sobrevoando o texto, aérea, até mesmo desconectada do mundo, plano de fundo da chamada realidade. Tal interpretação faz sentido na medida em que no texto a professora não defende a conciliação, antes a critica de modo claro e demarcado teoricamente. Ou seja, a construção de sua representação visual da professora indica uma direção oposta ao conteúdo verbal da sua entrevista. O que essa possível interpretação nos indica? 
Na figura 02, o jornal traz a fotografia de dois professores sendo apresentados a uma nova tecnologia de visualização a ser adquirida pela UFG e utilizada em sala de aula, chamada de projetor interativo. No canto esquerdo, tem um possível profissional que demonstra a tecnologia, posto que tem à sua mão uma caneta com a qual desenha na tela, sem tocá-la. Logo, um pouco mais à direita um jovem professor, olha com interesse a demonstração, pendendo seu corpo para mais perto da tela, a fim de ver melhor. Mais à direita, com uma postura corporal um pouco recuada e expressão facial denotando certo receio, uma professora, não tão jovem quanto o professor, observa com atenção. A fotografia não está no centro-superior da página, onde está outra fotografia cujo ator principal é o reitor, o gestor de maior poder, da UFG. Em dimensões menores que a imagem do reitor, esta está no canto inferior direito da página, mas é preciso considerar que este local é tido como privilegiado para arrematar as ideias de um texto, uma vez que, no ocidente, o lemos da esquerda para a direita, de cima para baixo.

O conteúdo do texto, em formato de matéria, assinada por uma profissional do jornalismo, aborda a importância do planejamento anual das unidades acadêmicas da instituição. Está presente, portanto, no fechamento da ideia, a de que uma UFG que, na sua semana de planejamento, planeja bem seu ano letivo, seus recursos financeiros e humanos por meio da qualificação que este momento pode proporcionar, promove uma instituição de ensino literalmente superior por meio das tecnologias audiovisuais educacionais, com acesso à internet, a rede mundial de computadores. Fica claro, nesta interpretação, que a atual gestão da UFG, intenciona que seus professores tenham acesso a esta novidade tecnológica, mesmo que a fotografia nos diga que ambos professores não são familiares a ela, tanto pela postura curiosa, quanto pela receosa.

A figura 03 apresenta uma recorrência em representações de professores no Jornal, em outras imagens que não compõem esta edição de análise. Nas fotografias das duas professoras, uma no canto superior esquerdo, outra no canto inferior direito, apresentam-nas pelo instante real do debate, seja pela postura gestual, mãos e gestos que usamos para nos fazer entender, seja pela expressão facial, os lábios entreabertos, a posição do pescoço e queixo. A fotografia de instante sugere, dentre outras coisas, que o fato aconteceu, foi do modo como está na imagem e que o fotógrafo apenas captou o momento, interferindo nele muito pouco. Esta compreensão é perigosa, na medida em que sugere que não há edição de imagem, o que implica em uma neutralidade do olhar do fotógrafo sobre o fato. É consenso, entretanto, que esta concepção é equivocada. Nas três fotografias sejam em formato de retrato, ou seja, o enfoque está na pessoa retratada, os três personagens estão nas mesmas dimensões, cor - tons de cinza, em local similar - centro-superior da página dupla do jornal e na composição tem o microfone, representado pelo direito de voz, contudo, a postura corporal, os ombros 
recuados do coordenador Vidal Barbosa e uma de suas mãos escondida sob a mesa contrapõe-se à tranquilidade e leveza com que a professora Celene Barreira, na fotografia abaixo da sua, argumenta. Em relação ao texto, noto que ele vem à Mesa-redonda solicitar, para as questões de moradia, apoio da academia, local do qual talvez não se sinta tão parte quanto a professora. Uma última observação sobre a representação das professoras, ambas por terem, nas fotografias, um microfone para cada, como disse anteriormente, representação muito recorrente em outras fotografias do jornal, denota que, durante toda a entrevista, elas puderam argumentar e intervir no direcionamento da mesa-redonda. Contudo, não é possível ter certeza, se a dinâmica da mesa-redonda permitiu este direito de voz e intervenção ocorreu em todo o tempo ou se as fotografias clicadas no instante em que cada um falou e diagramadas uma ao lado da outra, em um patamar de equidade, sugere um sentido diferente do ocorrido. Daí o perigo na concepção de que a fotografia seja a captação de um instante ocorrido.

Feitas estas três interpretações, retomo a discussão sobre o interesse de Penna (1992) em situar a discussão sobre a identidade, inserindo o sujeito que age no social e cultural, de modo a privilegiar abordagens teóricas que remetem à processos sociais, evitando reduções materiais. Para tanto, a autora pensa a identidade como representação, na medida em que se propõe a estabelecer um diálogo com a representação simbólica. Ela demarca o campo do simbólico inspirando-se em Cohen o qual o compreende como objetos, atos, conceitos e formas linguísticas que comportam uma diversidade de significados, emoções e sentimentos, que impelem os atores à ação, restringindo-se aos fenômenos objetivos - em oposição ao subjetivo - e coletivos - no sentido de público e observável. É a partir deste mesmo autor que ela vincula o simbólico às relações de poder, convidando para o diálogo Bourdieu com o qual conclui que classes e frações de classe estão em um jogo de força simbólica, pleiteando pela imposição da definição simbólica mais conveniente aos seus interesses. Com Geertz, a autora busca compreender o simbólico a partir da abstração da experiência percebida pela coletividade sobre suas atitudes, julgamentos e crenças. Por isso, a autora argumenta que tanto o pensamento, quanto as representações concretas dele, se constituem e são constituídos socialmente, ou seja, ao mesmo tempo que são construídos coletivamente, constroem sentidos simbólicos no coletivo. Penna (Idem, p. 59) conclui,

A atividade estruturante dos agentes, portanto, não é totalmente livre nem puramente pessoal ou individualizada; para não alongar a discussão, simplesmente porque sua atuação não se dá num vazio, mas num mundo social já simbolizado, um mundo em movimento, carregado de significações coletivamente estabelecidas. [...] Construções simbólicas, construções mentais, as representações são instrumentos de apreensão da realidade, sendo, em relação à sua complexidade, construções redutoras. 
Por último, a autora relaciona a identidade social a uma construção simbólica, ou seja, a uma representação que constrói sentido socialmente, na medida em que explica e interpreta o mundo a partir das práticas sociais de seus atores. Por isso, entende que ao demarcar fronteiras de seus limites, construindo sentido sobre como são representados, um grupo social está também construindo sentido sobre aqueles não representados como nós são designados os Outros. Desse modo, a autora (Idem, p. 60) finaliza "toda representação é construída através de um processo de seleção e esquematização, podese dizer que compõe um 'ponto de vista', uma redução da realidade".

A partir desta reflexão, podemos afirmar que a representação, nos termos de Penna, destes professores, aqui interpretadas a partir de fotografias veiculadas no Jornal UFG, contribui para a construção de uma identidade comum, como a do professor universitário? E podemos compreender que esta comunidade de professores, inserida na comunidade acadêmica, tem identidade cultural, nos termos de Lap?

\section{Identidade versus papéis}

A fim de buscar pistas que direcionem à respostas das questões anteriores, acrescento agora trechos de outros sujeitos entrevistados, com base na mesma pergunta anteriormente posta "Você se considera educador/a?".

Sujeito 4: Eu trabalho das 7 h00 da manhã às 6 h00 da tarde, à noite e no final de semana se eu quiser - e eu acho que devo - dar uma qualidade ao meu ensino e eu quero eu meu aluno tenha. Não adianta eu buscar, eu aprender se eu não conseguir passar isso para ele. Isso tem um preço e ele é alto, pensando em números horas do dia, então o nosso na verdade não é tripé, seria o "quadripé" porque é administração, é o ensino, é a pesquisa e é a extensão [...] mas a nossa escola nos cobra uma responsabilidade no administrativo muito grande e eu não tenho a opção de dizer não, ela vem.

Sujeito 5: Eu quero falar em relação a pesquisa também, pois a fala das duas [Sujeitos 1 e 3, trecho editado] mostrou que elas conseguiram crescer muito [após ingressar na UFG]. Foi o que eu entendi aqui com a pesquisa. Eu costumo brincar que faço pesquisa apesar da UFG porque a gente tem uma dificuldade muito grande e não é uma questão de dinheiro, tenho dois editais grandes aprovados com dinheiro com os quais eu compro equipamentos. Não tenho todos os equipamentos porque a instalação da escola é ruim. Eu instalo os experimentos na casa de vegetação, um cidadão entra lá e joga todos os vasos no chão [...] eu vim da USP, então a gente tinha a disponibilidade de todo equipamento possível.

Sujeito 6: Eu queria só falar, eu acho chato falar disso, mas eu vou falar, tem muita gente nova chegando, pessoas que estão fazendo doutorado e se acham como se fossem oráculos, né? Eles se sentem num plano transcendente. Falo sobre a questão da ética. Eu acho importante dizer porque são profissionais que estão 
cheirando a leite, desculpa o termo, mas é verdade. Passaram pela graduação, fizeram o mestrado e estão concluindo o doutorado e, na verdade, não têm experiência de mercado, de relações humanas, de respeitar colegas [...] acho que o professor tem que zelar também pela vida fora da universidade, você não está somente aqui dentro da universidade, mas a relação professoraluno, entrou na sala, é professor-aluno. Saiu, tudo bem, pode jogar uma partida de futebol.

Sujeito 2: O nosso ministro outro dia falou "nós não somos professores do século XXI, nós estamos no século XX e o aluno é do século XXI". Não sei se vocês viram que o Mercadante falou isso, o nosso ministro. Aí eu faria uma pergunta para ele: se nossa estrutura qualitativa é do século 19 , não é nem do século 20 , é do século 19, como sermos do século 21? Eu não consigo dar uma aula interativa porque eu não tenho uma sala de aula com uma estrutura interativa. Eu tenho uma sala de aula tradicional com quarenta a cinquenta carteiras, uma atrás da outra e um quadro de giz branco que não se usa mais em lugar nenhum do planeta [...] ai eu posso citar que ela [Sujeito 5] conhece a estrutura da USP, por exemplo. Você chega lá dentro tem telas interativas, tem disposição do conjunto da sala de aula em mesas e cadeiras com as quais você pode interagir, pode propor um trabalho discursivo e também um estudo de caso naquela mesma aula.

Sujeito 7: Estou em uma Unidade antiga também com uma cultura muito complicada, temos problemas estruturais antigos, mas formamos um egresso que está conectado com o mundo.

Além disso, o aluno que vem estudar aqui já é muito conectado com tudo que há de novidade em termos de tecnologias da comunicação. Aí ele tem uma perspectiva diferente, ele espera ter uma formação apenas técnica e isso precisa ser desconstruído logo no começo do curso. Eu escutei, semana passada, de um aluno de primeiro período assim "eu vim aqui para aprender uma profissão, esse é um curso técnico e eu não estou aprendendo minha profissão, tenho apenas disciplinas como Cultura Brasileira, Sociologia, Filosofia, em que isso vai me ajudar ser um bom profissional?". Aí temos que desconstruir essa visão tão estreita do que pode ser a formação universitária. Tem sido com isso que me comprometo, pois penso que assim estou sendo educadora.

Sujeito 5: Com toda a estrutura da USP, eu tive as aulas mais arcaicas que um professor pode dar. Então por mais que ela tenha toda estrutura, a cabeça da instituição USP e a forma como as aulas são dadas para mim é extremamente arcaica, o que eu não gostaria de repetir aqui na UFG [...] Eu funciono por encantamento, então o que eu gosto e o que eu acredito, eu faço. Na sala de aula eu gostaria de fazer a mesma coisa, de poder motivas os alunos a ponto de eles fazerem as coisas por eles mesmos e de trazerem uma nova proposta. Eu não acredito na proposta que a gente tem hoje na educação, eu acho que não funciona [...] eu tenho tentado trazer proposta diferentes, todo semestre eu tenho feito isso. Esse semestre eu comecei dizendo "como vocês querem ser avaliados?" e eles optaram como eles queriam. A única coisa que eu disse, "eu vou ser tão criteriosa numa avaliação de trabalhos quanto numa prova. Então não adianta falarem 'a gente quer trabalho porque é mais fácil' pois não vai ser bem assim". Teve grupos que fizeram trabalhos lindos, que ficaram ótimos e que chegaram ao final e 
falaram "nossa professora, passei!". Sabe como é que é: ver que a pessoa pegou o bichinho da curiosidade e cada vez que olhou aquele objeto sentiu como podia ser, como podia trabalhar. Mas sinto ainda que tem muita gente que não consigo acessar, encantar. Essa acho que é a maior angústia que eu tenho na sala de aula [...] eu tenho um relacionamento bem próximo dos alunos mas ainda me angustia bastante o fato de não conseguir uma metodologia de trabalho que seja menos imposta. [...] Bom eu tenho várias angústias na sala de aula. Eu me considero uma educadora, mas eu tenho certeza que eu sou uma pessoa em construção, nesse momento. Então não sou uma educadora, mas sou uma educadora em construção. Nem de longe cheguei perto de onde eu gostaria de estar, então uma coisa que me aflige muito é essa questão da pressão que com certeza dificulta o andamento do processo educacional, que é o fato de que a educação vem como uma imposição. A gente chega na sala de aula, tem que fazer uma chamada para ver se o aluno está vindo porque talvez ele não esteja. Isso me incomoda muito. Eu não gosto dessa imposição ao meu aluno. Ele ter que estar ali porque senão vai ficar com falta. Eu faço a chamada, mas se o aluno reprovar por falta, eu não o reprovo.

Sujeito 6: Eu me considero. E faço exatamente o contrário do que fizeram comigo, tudo o contrário porque tive muitas aulas expositivas e pouco debate [...] em algumas disciplinas eu acho que tem que ter debate, ter até para a Contabilidade. Como desenvolver o senso crítico do aluno se você não o deixa falar? Então eu faço muitas provocações. Àqueles mais calados eu pergunto "o que você acha disso, o que você acha que está acontecendo com a taxa de juros? O governo diminuiu a taxa de juros e aí, o que você acha?" [...] na minha época, por exemplo, me recordo de uma vez que fomos apresentar um seminário de economia do setor público com um professor que tinha alguns problemas. Primeiramente não dirigia, pois teve traumas em um acidente, então ele era muito ríspido com todos, muito mal humorado. Fomos apresentar esse seminário e aí o grupo não se preparou direito e era sobre Bresser Pereira, o estado na visão do Bresser não é tão simples, é complexo. E aí fomos apresentar e ele disse "Para, para, para! Zero para todo mundo. Próximo grupo". E aí eu achei muito unilateral. Eu acho que é importante o aluno mesmo no ridículo passar por aquele momento, mesmo que se humilhe, mas que apresente, mesmo que seja aquela porcaria. Depois você vem falando de alguns problemas que não podem existir. Então mostra para o aluno o erro dele, os problemas da apresentação, a superficialidade, a falta de pesquisa, a falta de argumentação e a falta de postura. Então isso é importante porque eu acho que o educador vai além dos manuais, pois os manuais são muito deficientes. Eu não costumo ficar preso aos manuais, o professor vai além deles [...] muitos alunos têm aquela ideia de cursinho de modelismo, o livro me salva, não o livro não é panaceia para resolver os problemas, porque o meio acadêmico é um meio que te permite fugir um pouco dos modelismos e dessa questão muito presa, própria do ensino médio [...] então eu sou muito dessa visão, eu faço o avesso do que fizeram comigo. 
Castells (1999, p. 22) entende identidade como "a fonte de significado de um povo" e também o "processo de construção de significado com base em um atributo cultural, ou ainda um conjunto de atributos culturais inter-relacionados, o(s) qual(ais) prevalece $(\mathrm{m})$ sobre outras fontes de significado". Para o autor, a identidade pode ser múltipla, embora essa pluralidade seja "fonte de tensão e contradição tanto na autorepresentação quanto na ação social" (Idem, ibidem). Por isso, para ele a identidade precisa ser distinguida dos papéis sociais ou do conjunto de papéis sociais, os quais "são definidos pelas normas estruturadas pelas instituições e organizações da sociedade" de modo que a influência destes no comportamento das pessoas depende de negociações entre os indivíduos que os exercem e as instituições (Idem, p.23). Assim exposto, conclui que "identidades, por sua vez, constituem fontes de significado para os próprios atores, por eles originadas, e construídas por meio de um processo de individuação" e distingue argumentando que "identidades são fontes mais importantes de significação do que papéis" uma vez que "organizam significados, enquanto papéis organizam funções" (Idem, ibidem). O autor, para fins de esclarecimento, define "significado como a identificação simbólica, por parte de um ator social, da finalidade da ação praticada por tal ator" o qual "organiza-se em torno de uma identidade primária (uma identidade que estrutura as demais) auto-sustentável ao longo do tempo e do espaço" (Idem, ibidem, grifo do autor), argumentando estar concentrado, ao abordar a questão, na identidade coletiva e não na individual.

Delimitando seu campo de abordagem, a identidade coletiva, o autor argumenta já ser consenso que ela é construída a partir do que nomeia de matéria-prima que classifica como a história, o contexto geográfico, a memória coletiva, as instituições que as produzem e reproduzem, as fantasias pessoais, os aparatos de poder e revelações religiosas que as envolvem. Toda essa matéria-prima reunida, expõe, torna um material processado ao entrar em contato com os indivíduos, grupos sociais e sociedades que o fazem reorganizando seus significados com vistas em seus projetos culturais, visões de tempo e espaço. Por isso, Castells (Idem, pp. 23-24) conclui que

quem constrói a identidade coletiva, e para quê essa identidade é construída, são em grande medida os determinantes do conteúdo simbólico dessa identidade, bem como seu significado para aqueles que com ela se identificam ou dela se excluem.

Expondo a compreensão de Castells, poderíamos pensar a identidade a partir da imagem do guarda-chuva, dentro da qual se abarcam todos os papéis que vivenciamos: mãe, professora, esposa, espiritualista, filha, pesquisadora, etc. Neste sentido, que relação estes papéis estabelecem com a minha identidade? E ainda, eles podem alterá-la, modificá-la? 
Para refletir sobre estas questões, gostaria de fazer uso de outra imagem. Ao invés da metáfora do guarda-chuva, usaria a da máscara, movida pelo interesse de pensar que para o exercício de cada um destes papéis, elejo uma que, independente de qual, é constituída não apenas pela minha identidade pessoal, mas também por normas estruturadas institucionalmente, que se tornam significativas socialmente e podem ser designadas por identidades coletivas. Exemplifico. Noto que deste segundo trecho de depoimentos, outra temática emerge: a interferência das normativas institucionais no exercício de ser professor/a universitário/a. Por exemplo, designação de educador, para o Sujeito 6, está relacionada não apenas à normativas institucionais estabelecidas oficialmente, mas também à negação da postura pessoal de um professor, que usa como exemplo, a fim de mostrar o que não considera ser educador. Para o Sujeito 6, o erro e o ridículo devem ser incluídos no processo educativo. Neste caso, quando uma pesquisadora, próxima a mim, defende que não é possível tratar de identidade pessoal e simultaneamente da identidade social, noto um problema. Como a partir de sua afirmação compreendo, considerando este relato, que a auto-atribuição de educador para o Sujeito 6 se constrói pela negativa de uma postura pessoal de um professor seu?

Neste mesmo sentido, um pouco mais acima, o mesmo Sujeito 6 argumenta que o professor, que para ele é sinônimo de educador, tem que zelar pela sua vida fora da universidade, evitando envolvimentos com alunos além do que ele chama de "normal", que seria o aceitável para que dentro de sala de aula não haja privilégios para alguns alunos numa relação, que precisa ser ética, entre todos os alunos e o professor. Por ética aqui, ele parece entender que o professor, que é educador, deve permitir que o aluno se exponha ao erro para ser corrigido. Não se trata, pelo contexto do seu argumento de exercer sobre este aluno o poder da correção pública, gerando uma situação humilhante. Mas o contrário disso. Trata-se de respeitosamente dar ao aluno o direito de voz, mesmo que em seu processo de expressá-la, ele cometa equívocos. O que ele parece não abrir mão é da responsabilidade em dar um retorno a este aluno, pontuando respeitosamente seus equívocos. Talvez esta representação do que é um educador ou professor seja altruísta para alguns, mas para ele, que viveu a experiência de ser reprimido de errar, num processo de aprendizagem, não parece se tratar disso, antes da compreensão do que é aprender. Hoje, ele, professor universitário que se designa educador, foi um dia, em um seminário, um aluno que recebeu um zero. Para ele, a auto-atribuição de educador e professor é mediada por uma experiência pessoal, vivida enquanto exercia o papel de aluno. Daí fazer sentido a afirmação de Souza e Diehl (2012, pp.4-5)

Entendo a identidade para além de um elemento construído a partir das relações pessoais internas com o mundo, algo fundamental para que cada um possa entender qual seu papel diante de uma sociedade construída. A identidade de cada um 
muitas vezes pode se tornar o reflexo do meio onde o indivíduo vive e atua socialmente. Assim, compreendo que a cultura está diretamente atrelada à busca de sentido e significado da identidade pessoal.

Esta compreensão de identidade não desconsidera a relação entre o individual e o social, antes nos permite problematizar como ambos podem estar mais imbricados quanto nos parece. Por isso, me pergunto, quando Castells distingue o papel social da identidade social, ele estaria nos dizendo que o exercício de papéis sociais, como o ser professor, não constitui por si só nossa identidade? Parece-me que sim. Em outras palavras, quando o Sujeito 4 afirma que para ser educadora/a destina das 7 da manhã às 6 da tarde e também à noite e nos finais de semana para dar conta desta empreitada, não estaria aqui explícito que se trata de algo bem maior do que um papel, uma vez que ele passa a ser exercido, quase em tempo integral? Com este relato, tem-se outros fatores que carecem de observação, ser professor/a universitário, para o Sujeito 4, extrapola e muito o momento da sala de aula, pois parece se considerar educador/a quando exercita também a pesquisa, a extensão e o fardo do administrativo, que chama de "quadripé", do qual não consegue se desvencilhar.

Sem a intenção de mapear na IES estudada sobre a sobrecarga do administrativo no trabalho de seus professores, este relato explicita que o ser professor envolve muito mais do que o momento da sala de aula, no contexto da universidade. Dele, é exigido além do ensino, a pesquisa, a extensão e a administrativo. Assim, ser professor/a universitário/a hoje implica em questões muito mais amplas e complexas do que supomos. É preciso ainda dizer que estas questões estão intimamente ligadas a políticas do ensino superior no Brasil, as quais por meio de órgãos reguladores têm cobrado uma produtividade nunca antes vista, sem, contudo, oferecer condições mínimas de trabalho. Esta constatação pode ser notada na afirmativa do Sujeito 2, o qual pergunta ao Mercadante se a infra-estrutura das universidades dão conta do século XXI. Obviamente, o relato é irônico.

Em termos de artefato visual, no Jornal da UFG, a postura dos professores na Figura 02, diante do projetor interativo, demonstra pouca proximidade com a tecnologia, que para o Sujeito 2, seria uma resposta à provocação do Mercadante, ou seja, "se nossa estrutura qualitativa é do século 19, não é nem do século 20 , é do século 19 , como sermos do século 21?". Em outras palavras, a identidade do professor universitário, a partir da fala do Ministro trazida pelo Sujeito 2, é arcaica. Pergunto, mas se o é de fato, quais são os fatores implícitos? Para o Sujeito 2, trata-se da falta de estrutura que o próprio financiador da educação pública no Brasil, o governo, se omite a fornecer. Por isso, o Sujeito 2 devolve a provocação ao Ministro. Este relato dá conta de uma noção de 
notória que a universidade pública ainda sente as consequências da falta de investimento, por longos anos de sucateamento. A greve dos professores universitários, que neste ano de 2012, foi deflagrada em mais de 54 IES do Brasil, relatam um pouco sobre este descaso governamental.

Mas ainda é preciso ressaltar que apesar do Sujeito 2 e o Sujeito 3 advertirem a necessidade de tecnologias para o ser educador/a, o Sujeito 5 traz outra faceta sobre a mesma questão. Quando apresenta que teve experiências acadêmicas na USP, com as tecnologias de ponta, todas disponíveis, demonstra sua frustração ao afirmar que "com toda a estrutura da USP, eu tive as aulas mais arcaicas que um professor pode dar". Para este Sujeito 5, ser educador/a é mais do que dar acesso a tecnologias de ponta, é estimular que o estudantes se envolva no processo de aprendizagem. Obviamente, o Sujeito 5 não está abrindo mão das tecnologias, pois afirma um pouco antes, ter editais com recursos para realizar suas pesquisas, mas que busca algo mais, que chama de acessar o/a estudante por meio de construções de aprendizagens menos impostas e mais participativas.

Desse modo, o Sujeito 5 constrói sua auto-atribuição também pela negativa da postura arcaica de seus professores pessoais. Assim, por mais que tenha tido estrutura física qualificada, argumenta que ela não dá conta de um processo educacional que acesse os alunos, promovendo neles a curiosidade pelo saber. Desse modo, pelo seu exemplo anterior sobre as falhas nos seus experimentos de pesquisa, atribui aos recursos humanos a maior responsabilidade pelo projeto educacional promover acessos ou não. Desconfia, neste sentido, das normativas institucionais a ponto de burlá-las ao seu modo, como o faz com a questão da chamada. Enfim, parece compreender a representação de um educador como um sujeito pronto e certo de suas ações, por isso, se auto-atribui não uma educadora, mas "uma educadora em construção". Relacionando as recorrentes imagens institucionais, como as veiculadas no Jornal UFG, analisadas acima, noto que tal representação tem eco na ilustração 3 , na qual as professoras são apresentadas muito tranquilas e seguras do seu papel, em detrimento do coordenador, que está com ombros encolhidos. Esta representação ante a um microfone, que significa seu poder de voz, tem sido uma das representações mais construídas do professor, de modo que esta suposta certeza e segurança passa a ser um consenso coletivo em relação ao professor. Assim, quem não compartilha destas certezas, como o Sujeito 5, por duvidar de normativas impostas por não as ter internalizado, sente-se deslocado em relação a representação hegemônica do que é ser professor/a universitário/a.

\section{A opção pelo entrelugar na pesquisa em cultura visual: implicações finais}

Durante o levantamento bibliográfico e leitura dos textos com os quais dialogaria 
na produção desta reflexão, meus questionamentos oscilaram entre dúvidas, inseguranças e limites que cerceariam minhas inquietações, ao relegá-las à hermetismos do conhecimento. Exemplifico lembrando-me de uma colega pesquisadora quando discutíamos o conceito de identidade a partir de leituras realizadas - algumas das quais serão abordadas aqui - observou "deixemos as questões da identidade pessoal para a psicologia e psicanálise, estamos aqui tratando da identidade social". Quão frustrantes foram, num primeiro momento, estas palavras.

Não que eu estivesse buscado o conceito de identidade para me sentar no divã e resolver problemas pessoais (não seriam profissionais?, esta confusão é sintomática!) com os alunos que chegam em minhas aulas, em uma graduação em Comunicação Social - Publicidade e Propaganda, na qual tenho trabalhado, nestes últimos anos, com disciplinas de Teorias da Imagem, Laboratório de Documentário, Saberes Audiovisuais Colaborativos e Aprendizagens Audiovisuais Cotidianas. Até porque para discutir minha relação pessoal com os alunos, talvez fosse mais profícua uma terapia de grupo, na qual eu e eles pudéssemos dialogar, ao invés de produzir este texto, elaborado sob pressupostos científicos ${ }^{3}$.

O objetivo do projeto de pesquisa com o qual esta reflexão busca contribuir consiste em buscar pistas que tornem possível a construção de aprendizagens audiovisuais no ensino superior que ultrapassem certo tecnicismo instrumental vigente e estimulem a expressão subjetiva e experimental dos estudantes. Desse modo, a pesquisa engloba as descobertas de aprendizagens discentes na relação com as minhas próprias expressões audiovisuais e docentes. Neste contexto de entrelugar, nem é apenas a observação dos processos de aprendizagem dos discentes que interessam, mas também a relação destes com os meus processos de aprendizagem como docente e as autodescobertas do meu papel de professora.

A perspectiva epistemológica com a qual o projeto de pesquisa se vincula é o campo de estudos da Cultura Visual. Segundo Monteiro (2008, p. 131), trata-se de "um novo campo acadêmico marcado pela interdisciplinaridade", que "se ocupa da diversidade do universo de imagens" e emerge num cenário "em que a história da arte, a antropologia, a linguística, os estudos de cinema e a literatura comparada encontram a teoria pós-estruturalista e os estudos culturais". Segundo Mitchell (2003) o conceito de Cultura Visual pode abarcar o campo de estudos visuais da cultura, bem como os artefatos visuais desta cultura. Valcárcel (2000) apresenta o pós-estruturalismo como a

Obviamente, ao afirmar isso, não estou eliminado a prerrogativa do diálogo em textos construídos sob tais pressupostos, afinal esta produção de conhecimento se estabelece a partir de diálogos, presentes nela no formato de citações. Contudo, ressalto a diferença que se estabelece quanto aos recortes, ênfases, interpretações e afiliações de um texto científico produzido solitariamente e as possibilidades de intervenções, redirecionamentos e rupturas que um diálogo em grupo possibilita. 
crítica teórica da cultura pós-moderna, que juntas configuram um novo tempo, a pósmodernidade. Para o autor, apresentado aqui em linhas gerais, a filosofia pós-moderna critica o racionalismo positivista - suas noções de razão, construindo a negação de pretensões teóricas universalistas e totalizadoras - bem como a cultura racionalista, preferindo sugerir que a objetividade científica precisa ser colocada entre aspas e a ciência compreendida como um discurso.

Tal fundamentação epistemológica permite a apropriação da bricolagem como perspectiva metodológica para a referida pesquisa. Kincheloe (2007, pp. 15-16) se utiliza da palavra francesa bricoleur, no espírito do antropólogo Lévi-Strauss, para descrever "um faz-tudo que lança mão das ferramentas disponíveis para realizar uma tarefa", de modo a considerar que o processo de pesquisa, em um contexto tão complexo como o atual, carece de métodos ecléticos para, ao invés de explicar o mundo real, destacar "o relacionamento entre as formas de ver de um pesquisador e o lugar social de sua história pessoal". Neste sentido, para o autor, a abordagem metodológica é, ela mesma, um processo cognitivo que "envolve construção e reconstrução, diagnóstico contextual, negociação e readaptação" no qual a interação do pesquisador com os objetos - para este projeto, os sujeitos - da investigação é "complicada, volátil, imprevisível e, certamente, complexa", uma vez que está claro que a vida cotidiana está marcada por estruturas sociais complexas (Idem, p. 17).

Sem a intenção de esgotar tanto a fundamentação epistemológica, quanto a perspectiva metodológica da pesquisa em curso nesta reflexão, torna-se necessário finalmente pontuar que a relação subjetiva da pesquisadora com os sujeitos envolvidos no campo de investigação é tão importante para a construção de sentido e de conhecimento, quanto a representação social do ser professor/a que permeia esta relação. Por isso, a problematização desta reflexão está situada em um entrelugar, que se refere a aspectos subjetivos em relação ao que está estabelecido socialmente sobre o ser professor.

Aprendi a ser professora observando os professores que tive ao longo da minha trajetória escolar, uma vez que cursei bacharelado na graduação. Hoje percebo que os procedimentos referentes ao meu exercício desta atividade se deram a partir do modo como imagino o que é ser professora universitária. Este modo é difundido por meio da atuação dos professores em sala, mas muito mais pelas diversas representações simbólicas difundidas socialmente. Assim, com este texto busco compreender como estas representações simbólicas constroem um ser professor e de que modo este ser professor, que argumento tratar-se de uma identidade construída culturalmente, se relaciona com a minha identidade pessoal de professora. A partir desta perspectiva de entrelugar, minha suspeita é que se torna inviável demarcar tão hermeticamente a fronteira da identidade 
cultural e a dos papéis exercidos socialmente, assim como a fronteira da identidade pessoal da representação social de ser professora universitária.

Na nossa língua portuguesa, quando perguntamos "o que você quer ser quando crescer?", está implícito, embora eu possa ser muitas coisas, isto é, ter vários papéis, que se trata de uma profissão. É como se para nós o papel e a identidade estivessem tão imbricados, que se torna impossível dizer onde termina um e começa o outro. Arendt (2003) argumenta que a glorificação do trabalho (ou labor, dependendo da tradução), na era moderna, teria elevado esta atividade humana acima das demais, de modo a quase pensarmos que quem não trabalha não é. Obviamente, esta compreensão dá conta de como a distinção de Castells entre identidade e papéis é insuficiente para pensarmos o ser professor.

Interessa-me retomar os primeiros três depoimentos expostos para pensar nas seleções e esquematizações realizadas pelos sujeitos, para construir suas autoatribuições. Com base em quais representações estes sujeitos se auto-atribuíram diferentes uns dos outros? Aqui estas diferenciações parecem ter ocorrido com base em uma significação coletiva, como nos trouxe Lap, embora não consensual sobre como é representado socialmente o educador e o professor. Neste sentido, o Sujeito 3, reage ao mito sobre o Outro usado pelo Sujeito 2 para construir sentido no exemplo de que aprender sobre o social, além de ser uma bondade com a qual ele não se compromete, ocorre em contato com 'tribos indígenas', ou seja, com o diferente e, para ele, este contato é que seria capaz de educar.

Noto que enquanto para o Sujeito 2, o diferente e o errado não compõem seu projeto educacional, para o Sujeito 3, ser educador implica em ser perpassado por diferentes designações auto-atribuídas, como professora, pesquisadora, militante, ativista, mãe etc. Observo ainda que, quando o Sujeito 3 se apresenta como ativista do movimento negro e do movimento de mulheres, argumentando que esta atuação inaugura um diálogo político que atravessa seu suposto papel de educadora, de mãe e de professora na sua relação com o ensino e a aprendizagem dos alunos. Esta afirmação torna a separação tão demarcada por Castells entre identidade e papel um tanto frágil, na medida em que uma reconhecida identidade de resistência, como exemplo ativista do movimento negro e de mulher nos termos do autor, atravessa todos os papéis, ao mesmo tempo que, estes atravessam sua identidade de resistência.

Tendo também a concordar, para fins deste estudo, com a noção de Lap, para quem a identidade cultural das comunidades se diferencia segundo níveis, como família, raça, nação, religião, língua do mesmo modo que construímos a divisão do mundo em designações como oriente e ocidente, norte e sul. Neste sentido, a distinção entre papel social e identidade proposta por Castells traz a mim um problema, pois o Sujeito 1 se 
auto-atribui educador por formar seres humanos, ou seja, pelo que o autor concebe como papel. Também sobre isso, se o Sujeito 2 encarasse a profissão de professor como apenas um papel social, faria algum sentido se indignar com o Mercadante por qualificar os professores brasileiros de atrasados, do século passado? Talvez, por se tratar de apenas um de seus papéis, tal designação, mesmo vinda do Ministro não afetaria em nada sua identidade cultural. Mas parece que não foi bem isso o que aconteceu, uma vez que ele trouxe para uma entrevista, que sabia ser para fins de pesquisa e tinha conhecimento de que sua afirmação poderia se tornar pública.

Parece-me acertada, ainda, a afirmativa de Lap na qual o contato é que nos ajuda e nos obriga a nos conhecer e reconhecer o Outro, de modo que as diferenciações identitárias se estabelecem por meio da construção cultural sobre esse Outro, o que pode ser notado a partir das reações de designação do Sujeito 2 em relação ao Sujeito 1 e do Sujeito 3 em relação ao 2 . Além disso, parece que este contato ${ }^{4}$ proposto por Lap se estabelece no micro, por meio de relações pessoais, aqui ilustradas pelas entrevistas, e no macro, por exemplo, por meio dos meios de comunicação massivos ou direcionados, como podemos classificar, este último, o Jornal da UFG. Neste sentido, a afirmação da minha colega de que não estávamos tratando de identidade pessoal, mas social, torna-se suspeita, uma vez que observamos acima o quanto é tênue a relação entre a representação de uma identidade coletiva e a apropriação do indivíduo sobre ela. Retomo, como exemplo, o deslocamento do Sujeito 5 em relação a não se autoatribuir uma educadora, mas uma educadora em construção. De onde este Sujeito tirou a noção de que para ser educador, deve-se estar pronto e seguro? Acredito que não foi de sua individualidade apenas, mas de uma representação, construída socialmente, sobre como um educador é um sabe-tudo, pronto para os desafios da aprendizagem.

Desse modo, é um tanto difícil, em termos de identidade, demarcar até onde vai a individual e onde começa a social. Por mais que tentemos estabelecer este limite para fins de estudo, haverá um entrelugar onde estas duas identidades se encontrarão, confundindo-se. Este entrelugar, talvez, seja mais bem visualizado quando a partir da Penna, que compreende a identidade como representação. Neste sentido, o modo como os professores são representados, assim como os educadores, fazem eco nas práticas sociais dos professores/ educadores. Ou seja, no exercício de seus papéis sociais, elegem uma máscara que representa com mais afinidade aquilo que está construído socialmente sobre o que é ser professor. Desse modo, a imagem da máscara serviria para pensarmos de que modo a nossa identidade se relaciona com os papéis exercidos por nós

$4 \quad$ Obviamente não será um único contato como este capaz de construir a noção de identidade cultural para estes Sujeitos, mas certamente todos os contatos evocam a necessidade de rever como se relaciona com ela, o que implica em refletir como a constrói. 
professores universitários. Não seria tanto pela separação dos papéis de uma identidade que de fato produz significado, como afirmou Castells, mas como uma relação, que atravessada pela representação, torna nosso papel social também produção de sentido identitário.

Se tomarmos os papéis que exercemos como máscaras escolhidas para cada contexto normativo, poderíamos pensar que a troca delas só ocorre porque estas normas institucionais, que são também sociais, são distintas para cada um destes contextos. Por exemplo, o contexto acadêmico exige a máscara de mãe seja substituída pela de professora/pesquisadora, sob pena de inadequação aos grupos envolvidos, estudantes, colegas, instituição de ensino, órgãos reguladores, etc. A imagem, no entanto, não pressupõe uma identidade oculta, distinta e atrás dessas diversas máscaras, mas que o indivíduo observando e internalizando as normativas institucionais pressupostas socialmente para o exercício de determinado papel, eleja alguns aspectos de sua identidade a fim de exercê-lo.

Finalmente, gostaria de lembrar os artefatos da cultura visual, as fotografias do Jornal UFG, avaliando como elas constroem um ser professor/a universitário/a. O ser professor, representado por estes artefatos, é cordial e dócil, mesmo que sua perspectiva teórica, explicitada no texto, seja de confronto e com clareza política. É ainda representado como aquele que tem voz e é articuladamente seguro para fazer uso dela, o que pode ser reforçado pelo desconforto do Sujeito 5, ante suas incertezas, por isso afirma sobre si mesma "não sou uma educadora, mas sou uma educadora em construção", como se os demais professores universitários também não o fossem. De fato são, mas as representações sociais que são difundidas dizem muito mais das nossas certezas, do que das incertezas. Daí porque o ser professor universitário, na perspectiva do Planejamento anual da UFG, é aquele que vai aprender a lidar com a tecnologia de ponta, para ser atual. Aqui se mistura o discurso da excelência da gestão e do ensino, se, e somente se, tecnologizado. Mas esta questão pede outra reflexão.

\section{Referências:}

ARENDT, Hannah. A condição humana. Rio de Janeiro: Forense Universitária, 2003.

CASTELLS, Manuel. O poder da identidade. Vol II. São Paulo: Paz e Terra, 1999.

KINCHELOE, Joe. O poder da bricolagem: ampliando os métodos de pesquisa. In:

BERRY, Kathleen. Pesquisa em educação - conceituando a bricolagem. Porto Alegre: Artmed, 2007.

LAP, Ngo Tu. Identité culturelle: la relativité de la diversité. In: Diversité culturelle et mondialisation. Éditions Autrement: Paris, 2004.

MITCHELL, W. J. T. Showing seeing: a critique of visual culture. Journal of Visual 
Culture, n. 2, p. 165-181, jun. 2002.

MONTEIRO, Rosana Horio. Cultura visual: definições, escopo, debates. Domínios da Imagem, n. 2, p. 129-134, maio 2008.

SOUZA, Mariana Binato de; DIEHL, Viviane. Singularização de identidades e construção de subjetividades na perspectiva da cultura visual. Revista Digital do LAV - Laboratório de Artes Visuais, n. 8, p. 1-24, março de 2012.

ORTEGA VARCÁRCEL, José. Filosofías de la subjetividad: la crítica al racionalismo. In: . Los horizontes de la geografia. Barcelona: Editora Ariel, 2000.

PENNA, Maura. O que faz ser nordestino: identidades sociais, interesses e o "escândalo" Erundina. São Paulo: Cortez, 1992.

Lara Lima Satler (UFG)

Alice Fátima Martins (UFG)

Recebido em: 03/12/2012

Aprovado em: 13/02/2013 